Original Research Article

\title{
The study of effects of inhibition of the renin angiotensin system on memory in rats
}

\author{
Medhinee Kulkarni*, Prasad Pandit, Kiran Bhave
}

Department of Pharmacology, HBT Medical College and Cooper Hospital, Mumbai, Maharashtra, India

Received: 28 May 2018

Revised: 12 July 2018

Accepted: 26 July 2018

*Correspondence to:

Dr. Medhinee Kulkarni,

Email: dr.medhineekulkarni@ gmail.com

Copyright: () the author(s), publisher and licensee Medip Academy. This is an openaccess article distributed under the terms of the Creative Commons Attribution NonCommercial License, which permits unrestricted noncommercial use, distribution, and reproduction in any medium, provided the original work is properly cited.

\begin{abstract}
Background: The existence of an independent renin angiotensin aldosterone system (RAAS) has been well-established and is known to modulate various pathological processes such as neuroinflammation, neurodegeneration, and neural injury, in addition to the RAAS in the cardiovascular system.

Methods: Eighteen Wistar rats were divided into 3 study groups ( $n=6$; Losartan, Ramipril, Normal Saline), trained on the Cook's Pole climbing apparatus till the conditioned avoidance response (CAR) rate was $100 \%$. The retention of CAR was tested each week for 4 consecutive weeks. The number of times that the animal successfully avoided the shock, and the time taken for this avoidance were measured and compared with placebo (Normal Saline). The values have been expressed as Mean \pm Standard Deviation (SD). A p-value of less than 0.05 has been considered as significant.

Results: The retention of the conditioned avoidance response in the group receiving study drugs was significantly more than the placebo group. However, there was no show significant difference between Losartan and Ramipril in the rate of retention, or the time taken for avoidance.

Conclusions: In this study, Ramipril and Losartan have a beneficial effect on learning and memory as compared to plcebo.
\end{abstract}

Keywords: Cook's Pole-Climbing apparatus, Cognition, Losartan, Memory, RAS inhibitors, Ramipril

\section{INTRODUCTION}

The Renin-Angiotensin System (RAS) plays a critical role in the regulation of cardiovascular function and development of cardiovascular-related diseases. Although it is best established for its role in the control of blood pressure and management of heart failure, evidence obtained from animal experiments and clinical trials suggests that it is involved in complex brain functions. A complete renin-angiotensin system (RAS) exists in the brain, which is distinctly separated from the peripheral system and comprises all necessary precursors and enzymes required for the formation and metabolism of the biologically active forms of angiotensin. Independent from the circulating system, angiotensin (ANG) II is produced locally within the brain and has been implicated in cardiovascular regulation and a variety of other physiological functions.

Basic experiments suggest a role of brain angiotensin II in neural injury, neuroinflammation, and cognitive function and that RAS blockade attenuates cognitive impairment in rodents' dementia models of Alzheimer's disease (AD). 
The brain RAS has been highlighted as having a pathological role in stroke, dementia, and neurodegenerative disease. ${ }^{1}$ Therefore, RAS regulation is expected to have a role in modifying the course of AD.

Cognitive impairment and dementia are common serious health problems that impair quality of life in the elderly. Previous reports indicate the possibility that treatment with antihypertensive agents prevents the impairment of quality of life including cognitive performance. ${ }^{2,3}$ RAS blockade could have possible beneficial effect on preserving cognitive function as demonstrated by Wright and Harding, as well as Mogi and Horuichi in the clinical field. ${ }^{4,5}$ An epidemiological study by Li et al, showed that male subjects treated with ARBs exhibited a significant reduction in the incidence and progression of Alzheimer disease (AD) and dementia compared with those treated with ACEIs and other cardiovascular drugs. ${ }^{6}$ Interestingly, the inverse associations with $\mathrm{AD}$ were stronger for ARBs compared with ACEIs. In a subanalysis of the Study on Cognition and Prognosis in the Elderly (SCOPE) trial, hypertensive patients treated with an ARB Candesartan showed lesser decline of specific areas of cognitive function such as attention and episodic memory. However, almost all large clinical intervention trials have shown no significant difference in the incidence of dementia between treatment with ARBs or ACEIs and the placebo group. $^{7}$ This provides a sound rationale for the potential therapeutic effect of RAS inhibition in modifying the progress of $\mathrm{AD} .^{8}$

The incidence and prevalence of hypertension has been increasing steadily over the past few decades. It is now known to affect almost two-thirds of the population over the age of 60 years. ${ }^{9}$ Whereas the obvious benefits on cardiovascular and renal outcomes of commonly prescribed anti-hypertensive medications have been studied in great detail, relatively little attention is paid to other parameters such as cognition and memory. The most commonly prescribed ACE inhibitor in India is Ramipril, and Losartan in the most common ARB, according to a study conducted by Bajaj et al in 2012. Therefore, authors decided to evaluate these two drugs as a representative of their respective classes and their influence on cognition.

\section{Aims and objectives}

- To evaluate the effect of RAAS blockers (Ramipril and Losartan) on cognition in rats, using the Cook's Pole Climbing Apparatus

- To compare and evaluate the effect, if any, between these two drugs.

\section{METHODS}

All the experiments were carried out in accordance with the guidelines set by "Committee for the Purpose of Control and Supervision on Experiments on Animals" (CPCSEA), with prior permission of the Institutional Ethics Committee for Animal Experimentation. The study was carried out at Experimental Lab, Department of Pharmacology, T.N.M.C. and B.Y.L. Nair Charitable Hospital, Mumbai Central, Mumbai.

\section{Animal species for the study}

Eighteen Wistar rats, weighing 150-200 grams, were purchased from Haffkine Biopharma Corp Ltd., Mumbai. Each group consisted of 6 animals each. The animals were accommodated in polypropylene cages with grill on top and were identified by cage tag. They were given standard pellet diet, and purified water was provided in glass bottles with stainless steel sipper tubes.

\section{Study drugs}

All the study drugs were procured in the pure powder form from Cipla Ltd.

Dosages used in the study were as follows:

- Ramipril: $0.225 \mathrm{mg} / \mathrm{kg}$

- Losartan: $2.25 \mathrm{mg} / \mathrm{kg}$

- Normal Saline: $1 \mathrm{ml}$

The doses of the test drugs used are close to the lowest recommended anti-hypertensive doses of each drug in humans. All drugs were administered orally.

\section{Tests}

Cognition was evaluated by measuring the conditioned avoidance response (CAR) in rats as described by Cook and Weidley, using Cook's Pole Climbing Apparatus. The animals were subjected to a training schedule individually by placing inside the Perspex chamber of the apparatus. After an acclimatisation period of five minutes to the chamber, a buzzer was given for 5 seconds. Then, a shock of $1.5 \mathrm{~mA}$ was administered through the grid floor for 10 seconds. The rat will have to jump on the pole to avoid foot shock. Jumping on the pole functionally terminates the shock and this is classified as an Escape (Unconditioned Response). Such jumping prior to the onset of the shock was considered as Avoidance (Conditioned Avoidance Response - CAR). The session was terminated after completion of 10 trials for each animal. All the animals were trained prior to commencing the study, till they acquired $100 \%$ CAR.

Table 1: Study groups.

\begin{tabular}{|c|c|c|c|}
\hline $\begin{array}{l}\text { Group } \\
\text { no. }\end{array}$ & $\begin{array}{l}\text { Group } \\
\text { description }\end{array}$ & $\begin{array}{l}\text { Dosage and } \\
\text { route of } \\
\text { administration }\end{array}$ & $\begin{array}{l}\text { No. of } \\
\text { animals }\end{array}$ \\
\hline G1 & NS & $1 \mathrm{ml}(\mathrm{PO})$ & 6 \\
\hline $\mathrm{G} 2$ & Ramipril & $\begin{array}{l}0.225 \mathrm{mg} / \mathrm{kg} \\
(\mathrm{PO})\end{array}$ & 6 \\
\hline G3 & Losartan & $2.25 \mathrm{mg} / \mathrm{kg}(\mathrm{PO})$ & 6 \\
\hline
\end{tabular}


All the animals were trained prior to commencing the study, till they acquired $100 \%$ CAR. The same tests were repeated on days 7, 14, 21 and 28 after commencement of drug dosing. This methodology has been adopted and modified form a study conducted on extract of Vitis vinifera in rats by Sreemantula et al. ${ }^{10}$

The study was done with 3 groups (Normal Saline, Ramipril and Losartan) of 6 animals each. Identification by cage tag was done. Each group received the study drugs for a period of 4 weeks, and their ability to retain the Conditioned Avoidance Response was evaluated on day 7 , 14, 21 and 28. The parameters evaluated at each session were:

- The percentage of CAR (number of times the footshock was avoided by the animal)

- The time taken by the animal to jump on to the pole to avoid the shock.

\section{Statistical analysis}

The data were analysed by comparing with the control group by one-way ANOVA, followed by Tukey's post-hoc test. The results have been analysed with the aid of GraphPad Prism, version5. The values have been expressed as Mean \pm Standard Deviation (SD). A p-value of less than 0.05 has been considered as significant.

\section{RESULTS}

All the groups were comparable to each other in terms of time taken for avoidance at the end of training sessions ( $>0.05$ ). Time taken to avoid the foot shock at baseline was $3.89 \pm 0.228$ seconds. The following tables mention the retention of CAR, and time taken for avoidance by each group.

After one week of dosing, the animals were found to have $100 \%$ retention of the acquired reflex. The Losartan group, followed by the Ramipril group, performed significantly better than the Control group, in terms of time taken for avoidance (Table 2).

Table 2: Week 1.

\begin{tabular}{|llll|}
\hline $\begin{array}{l}\text { Group } \\
\text { no }\end{array}$ & Drug & $\begin{array}{l}\text { Time to } \\
\text { Avoidance (in } \\
\text { seconds) }\end{array}$ & $\begin{array}{l}\% \\
\text { retention of } \\
\text { CAR }\end{array}$ \\
\hline 1. & $\begin{array}{l}\text { Normal } \\
\text { Saline }\end{array}$ & $4.07 \pm 0.132$ & 100 \\
\hline 2. & Ramipril & $3.22 \pm 0.143 * * *$ & 100 \\
\hline 3. & Losartan & $3.25 \pm 0.178 * * *$ & 100 \\
\hline$* * *-\mathrm{p}<0.001$ & & \\
\hline
\end{tabular}

In the second week, the retention of CAR reduced, and simultaneously, the time taken for avoidance increased. The study drug groups had significantly shorter duration to avoid the foot shock. However, the retention of CAR was not significantly different between Ramipril and placebo groups (Table 3).

Table 3: Week 2.

\begin{tabular}{|c|c|c|c|}
\hline $\begin{array}{l}\text { Group } \\
\text { no }\end{array}$ & Drug & $\begin{array}{l}\text { Time to } \\
\text { Avoidance (in } \\
\text { seconds) }\end{array}$ & $\begin{array}{l}\% \text { Retention } \\
\text { of CAR }\end{array}$ \\
\hline & $\begin{array}{l}\text { Normal } \\
\text { Saline }\end{array}$ & $4.24 \pm 0.095$ & $76.67 \pm 5.16$ \\
\hline & Ramipril & $4.02 \pm 0.099 * *$ & $86.67 \pm 8.17^{[\mathrm{NS}]}$ \\
\hline & Losartan & $3.76 \pm 0.105 * * *$ & $90 \pm 6.33 *$ \\
\hline \multicolumn{4}{|c|}{$\begin{array}{l}* * *-\mathrm{p}<0.001 ; * *-\mathrm{p}<0.01 ; *-\mathrm{p}<0.05 \\
\text { NS - Not Significant }\end{array}$} \\
\hline
\end{tabular}

In the third week, the time for avoidance kept on steadily increasing, but the groups receiving the study drugs had a significantly shorter time as compared to placebo group. The retention of CAR was also significantly better in the drug groups as compared to the placebo groups (Table 4).

Table 4: Week 3.

\begin{tabular}{|lll|l|}
\hline $\begin{array}{l}\text { Group } \\
\text { no }\end{array}$ & Drug & $\begin{array}{l}\text { Time to } \\
\text { Avoidance } \\
\text { (in seconds) }\end{array}$ & $\begin{array}{l}\text { \% Retention } \\
\text { of CAR }\end{array}$ \\
\hline 1. & $\begin{array}{l}\text { Normal } \\
\text { Saline }\end{array}$ & $4.35 \pm 0.058$ & $66.7 \pm 8.17$ \\
\hline 2. & Ramipril & $4.21 \pm 0.119 *$ & $76.7 \pm 8.16 *$ \\
\hline 3. & Losartan $4.23 \pm 0.048 * *$ & $80 \pm 8.94 * *$ \\
\hline$* *-p<0.01 ; *-p<0.05$ & \\
\hline
\end{tabular}

By the end of the study duration, the time taken to avoid the foot shock was significantly shorter in the groups receiving Losartan and Ramipril as compared placebo, just as the retention was highest in the group receiving Losartan, followed by the Ramipril group (Figures 1 and 2). Predictably, the placebo group had the least retention of the conditioned avoidance response, and the highest time to avoidance (Table 5).

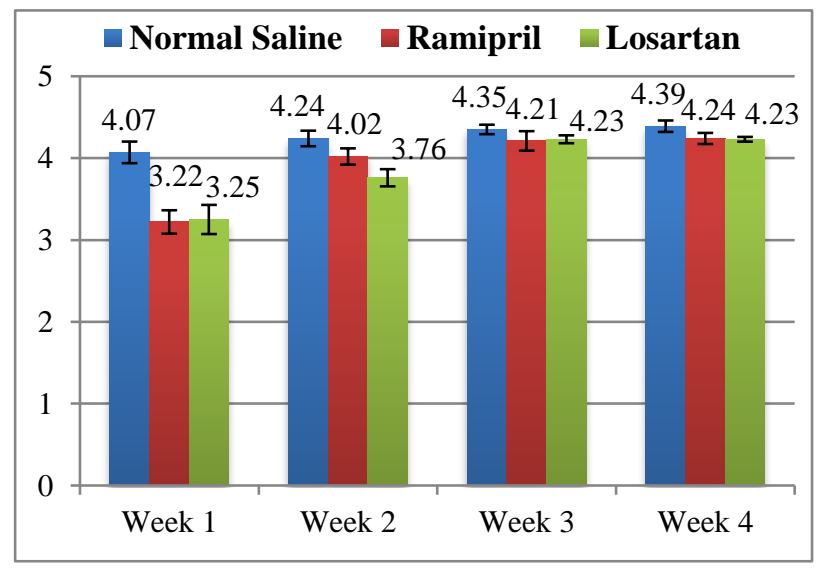

Figure 1: Time taken for avoidance over 4 weeks (mean). 
Table 5: Week 4.

\begin{tabular}{|llll|}
\hline $\begin{array}{l}\text { Group } \\
\text { no }\end{array}$ & Drug & $\begin{array}{l}\text { Time to } \\
\text { Avoidance } \\
\text { (in seconds) }\end{array}$ & $\begin{array}{l}\text { \% Retention } \\
\text { of CAR }\end{array}$ \\
\hline 1. & $\begin{array}{l}\text { Normal } \\
\text { Saline }\end{array}$ & $4.39 \pm 0.070$ & $56.67 \pm 8.17$ \\
\hline 2. & Ramipril & $4.24 \pm 0.068 * *$ & $65 \pm 5.48 *$ \\
\hline 3. & Losartan & $4.23 \pm 0.029 * *$ & $68.33 \pm 7.53 * *$ \\
\hline$* *-\mathrm{p}<0.01 ; *-\mathrm{p}<0.05$ & \\
\hline
\end{tabular}

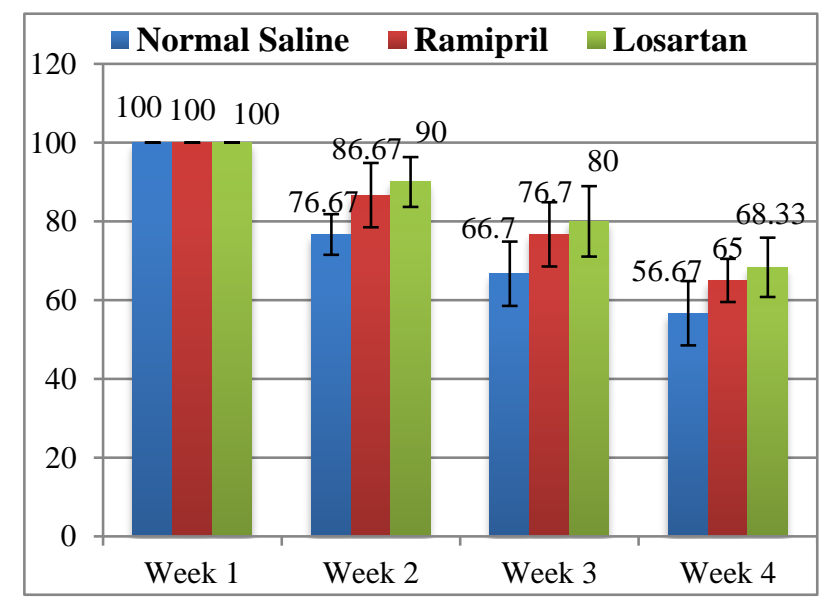

Figure 2: Retention of CAR in percentage over 4 weeks (mean).

\section{DISCUSSION}

Depending upon the type of information stored, memory can be of the following types: ${ }^{11}$

- $\quad$ Semantic memory: The memory for facts, numbers, dates, places and people

- Implicit memory: The memory for acquired skills such as walking, swimming, riding a bike, sewing, embroidery, etc

- Emotional memory: The memory of events that evoke intense emotional responses

There are various models to assess memory and cognitive abilities in animals. They are grouped as passive avoidance models, active avoidance models, and spatial learning. We chose the Cook's pole climbing apparatus as a model for learning and memory since it involves active learning of skill i.e., climbing onto the pole in order to avoid the unpleasant stimulus, and it provides for evaluation of retention of this learned response.

In this study we found that over a period of 4 weeks, all the animals demonstrated a rise in the time taken for avoidance and a reduction in the retention of CAR. However, this reduction was least in the Losartan group (reduced from $100 \%$ in the $1^{\text {st }}$ week to $68.33 \pm 7.53 \%$ at the end of $4^{\text {th }}$ week). The groups treated with Ramipril had intermediate retention (from $100 \%$ to $65 \pm 5.48 \%$ ).
One of the theories for neuronal loss causing cognitive decline is oxidative damage due to free radical generation. Bild et al, studied the effects of Captopril, Losartan, and Angiotensin II receptor blocker PD123177 on learning and memory, and concluded that angiotensin blockade by all three has a beneficial effect in the retention and recall of long term as well as short term memories. ${ }^{12}$ In vitro examination of hippocampus of these animals revealed less evidence of oxidative damage, as measured by less free radicals and more quantities of GS-SG (reduced glutathione peroxidase). Raghavendra et al, found out that Losartan yielded better results than Captopril in terms of acquisition and retention of memory. ${ }^{13}$ They propose that the beneficial effects could be due to anti-oxidant effects in addition to the inhibitory effects on the central RAAS.

Basso, et al evaluated the effects of Losartan and Enalapril on aging in mice and observed that the group which received Losartan from weaning had the best performance in terms of retention and recall of conditioned avoidance response. ${ }^{14}$ They proposed that Losartan has nitrous oxide (NO) donating/ releasing activity, which causes better blood flow and oxygen delivery subsequent to vasodilatation. Kume, et al studied the effects of Telmisartan on regional cerebral blood flow in hypertensive patients and concluded that it increases the blood flow to areas of the brain crucial in the cognitive process, namely the cingulate gyrus, and the hypothalamus. ${ }^{15}$ This result was independent of blood pressure lowering effect of Telmisartan.

Wang, et al demonstrated the beneficial effects of Valsartan in mice models of genetic Alzheimer's disease. ${ }^{16}$ They observed that Valsartan-treated animals had lower intra-cerebral $\beta$-amyloid deposits, and better spatial learning. Another proposed hypothesis is that Ang-II causes increased deposition of $\beta$-amyloid and phosphorylation of tau proteins. ${ }^{17}$ Phosphorylation of tau proteins is done by the enzyme glycogen synthase kinase $\beta$ 3. (GSK $\beta 3$ ). Administration of ACE-I Ramipril, Perindopril, and GSK $\beta 3$ antagonist caused a significant reduction of phosphorylation of tau proteins. Subsequently, it was noted that the disease progress slowed down considerably.

Tchekalarova, et al also established, through in vitro assays, that Ang-II receptor stimulation led to slowing down of long term potentiation. ${ }^{18}$ They treated the animals with Nifedepine, Telmisartan and Ramipril. Ramipril, followed by Telmisartan, had the maximum efficacy in antagonising the blunted LTP induced by Ang-II. A pilot study evaluating the effect of Ramipril in patients of mild hypertension, and with a positive family history of Alzheimer's disease was conducted in 2012. ${ }^{19}$

Efforts have been made by various researchers to elucidate the pathway of modulation of RAAS in learning and memory. A definite involvement of PPAR (Peroxisome Proliferator Activated Receptor) $\gamma$ has been unveiled. ${ }^{20}$ Low dose of Telmisartan facilitated working memory in 
the mice, an effect which was offset by co-administration of the PPAR $\gamma$ antagonist GW-9662. Higher doses (with or without the antagonist) caused worsening of the same parameters, due to reduced perfusion.

Additionally, Perindopril was found to be effective in reversing the cognitive decline due to Alzheimer's disease caused by low cerebral perfusion in rats. ${ }^{21,22}$ Dong et al, additionally demonstrated that this effect was not linked to dissolution $\beta$-amyloid deposits in the brain. ${ }^{22}$

\section{Strengths of the study}

Since anti-hypertensive drugs are required to be taken for prolonged periods of time, their effects on other functions attain particular importance. The effects on blood sugar and lipid levels, for instance, are well-established. The cognitive abilities of anti-hypertensive drugs get very little consideration before initiation of anti-hypertensive therapy. We therefore decided to evaluate cognitive effect of these drugs, which could impact the prescribing pattern of anti-hypertensive medications.

The model chosen was the Cook's Pole Climbing Apparatus, since it evaluates the conditioned avoidance response (CAR). CAR is a form of learning through negative reinforcement. In terms of learning, it reflects the declarative aspect of memory. This aspect is responsible for remembering facts, numbers and dates.

Drugs were administered for a period of 4 weeks, which is equivalent to a period of almost one and a half years in humans. $^{23}$

Blood pressure measurement was not done in this study. Therefore, an appropriate observation cannot be made with regard to the influence of blood pressure on cognitive function. Other aspects of memory, e.g., the spatial memory (which is important for driving, sports etc.) were not evaluated. The avoidance response of the animal on the Cook's pole climbing apparatus depends upon intact neuromuscular coordination. We have not evaluated the effects of any of the drugs with regards to their effects on neuromuscular coordination, and subsequent effects on their ability to jump up on the pole. Thus, this remains a potential confounding variable in this study.

\section{Direction for future research}

Evaluation of anti-hypertensive drugs in other animal models of learning and memory, such as Morris' water maze, Elevated plus maze, and other paradigms of active and passive avoidance.

Evaluation of other drugs of various classes on learning and memories. Establishing a relationship between dose of the drug used, and on cognitive abilities. Randomised controlled trials to evaluate the effects of anti-hypertensive drugs on cognition.

\section{CONCLUSION}

In this study, Ramipril and Losartan have a beneficial effect on learning and memory. The retention of learned tasks was significantly better with these drugs as compared to normal saline. However, comparison of Ramipril and Losartan did not demonstrate any statistically significant benefit of one over the other.

Funding: No funding sources

Conflict of interest: None declared

Ethical approval: The study was approved by the Institutional Ethics Committee for Animal Experimentation

\section{REFERENCES}

1. von Bohlen und Halbach O, Albrecht D. The CNS renin-angiotensin system. Cell Tissue Res. 2006 Nov;326(2):599-616.

2. Fogari R, Zoppi A. Effect of antihypertensive agents on quality of life in the elderly. Drugs and Aging. 2004;21(6):377-93.

3. Fletcher A. Quality of life in the management of hypertension. Clin Exp Hypertens. 1999 JulAug;21(5-6):961-72.

4. Wright JW, Harding JW. The brain RAS and Alzheimer's disease. Exp Neurol. 2010 Jun;223(2):326-33.

5. Mogi M, Horiuchi M. Effects of angiotensin II receptor blockers on dementia. Hypertens Res. 2009 Sep; 32(9):738-40.

6. Li NC, Lee A, Whitmer RA, Kivipelto M, Lawler E, Kazis LE, et al. Use of angiotensin receptor blockers and risk of dementia in a predominantly male population: prospective cohort analysis. BMJ. 2010 Jan 12; 340:b5465.

7. Mogi M, Iwanami J, Horiuchi M. Roles of Brain Angiotensin II in Cognitive Function and Dementia. Int J Hypertens. 2012;201(2):169649.

8. Albrecht D. Physiological and pathophysiological functions of different angiotensins in the brain. Bri J Pharmacol. 2010;159(7):1392-401.

9. Kotchen TA. Hypertension in Harrison's Principles of Internal Medicine Longo, Fauci, Kasper, Hauser, Jameson and Loscalzo (Ed.) $18^{\text {th }}$ Ed; McGraw Hill Publications; 2012:2042-2059.

10. Sreemantula S, Nammi S, Kolanukonda R, Koppula S, Boini KM. Adaptogenic and nootropic activities of aqueous extract of Vitisvinifera (grape seed): an experimental study in rat model; BMC Complementary and Alternative Medicine. January 2005:5:1.

11. Barrett KE, Barman SM, Boitano S, Brooks HL. Learning, Memory, Speech and Language in Ganong's Review of Medical Physiology $23^{\text {rd }}$ Ed., Tata McGraw Hill publications; 289-300.

12. Bild W, Hritcu L, Stephanescu C, Ciobica A. Inhibition of Central Angiotensin II Enhances Memory Function and Reduces Oxidative Stress 
Status in Rat Hippocampus; Progress in Neuropsycho pharmacology and Biological Psychiatry. June 2013;43(3):79-88.

13. Raghavendra V, Chopra K, Kulkarni SK. Comparative effects of Captopril and Losartan on Memory Enhancing effects using Inhibitory Shock Avoidance Paradigm in mice; Neuropeptides. Feb 2001;35(1):659.

14. Basso N, Paglia N, Stella I, deCavanaugh EM. Protective Effects of RAS on Aging; Regulatory Peptides. June 2005;128(3):247-52.

15. Kume K, Hanyu H, Sakurai H. Effects of telmisartan on cognition and regional cerebral blood flow in hypertensive patients with Alzheimer's disease; Geriatrics and Gerontology International. 2011 Sep 19.

16. Wang J, Ho L, Chen L, Zhao Z, Zhao W, Qian X, et al. Valsartan lowers brain $\beta$-amyloid protein levels and improves spatial learning in a mouse model of Alzheimer disease. The J Clin Investiga. 2007 Nov 1;117(11):3393-402.

17. Tian M, Zhu D, Xie W, Shi J. Central Angiotensin II induced Alzheimer's disease-like tau phosphorylation in normal rat brains. FEBS Letters, Oct 2012;586(20):3737-46.

18. Tchekalarova J, Albrecht D. Angiotensin-II suppresses Long term potentiation in lateral amygdala of mice via L-type Calcium channels; Neuroscience letters. Mar 2007;415(1):68-72.
19. Wharton W, Stein JH, Korcarz C, Sachs J, Olson SR, Zetterberg $\mathrm{H}$, et al. The effects of ramipril in individuals at risk for Alzheimer's disease: results of a pilot clinical trial. J Alzheimer's Disease. 2012 Jan 1;32(1):147-56.

20. Justin A, Sathishkumar M, Sudheer A, Shanthakumari S, Ramanathan M. Non-hypotensive dose of telmisartan and nimodipine produced synergistic neuroprotective effect in cerebral ischemic model by attenuating brain cytokine levels. Pharmacology Biochemistry and Behavior. 2014 Jul 1;122:61-73.

21. Yamada K, Horita T, Takayama M. Effect of a centrally active angiotensin converting enzyme inhibitor, perindopril, on cognitive performance in chronic cerebral hypo-perfusion rats; Brain Res. 2011 Nov 3;1421:110-20.

22. Dong YF, Kataoka K, Tokutomi Y. Perindopril, a centrally active angiotensin-converting enzyme inhibitor, prevents cognitive impairment in mouse models of Alzheimer's disease. FASEB J. 2011 Sep;25(9):2911-20. E-pub 2011 May 18.

23. Sengupta P. The Laboratory Rat: Relating Its Age with Humans Int J Prev Medic. 2013;4(6):624-30.

Cite this article as: Kulkarni M, Pandit P, Bhave K. The study of effects of inhibition of the renin angiotensin system on memory in rats. Int J Basic Clin Pharmacol 2018;7:1847-52. 